\title{
Neighborhood Environment, Active Commute, and Healthy BMI in Adolescents
}

\author{
Yehua Dennis Wei ${ }^{1}$, Weiye Xiao ${ }^{1, *(\mathbb{D})}$ and Ivis Garcia ${ }^{2}$ \\ 1 Department of Geography, University of Utah, Salt Lake City, UT 84112, USA; Wei@geog.utah.edu \\ 2 Department of City and Metropolitan Planning, University of Utah, Salt Lake City, UT 84112, USA; \\ ivis.garcia@utah.edu \\ * Correspondence: weiye.xiao@utah.edu
}

Citation: Wei, Y.D.; Xiao, W.; Garcia, I. Neighborhood Environment, Active Commute, and Healthy BMI in Adolescents. Sustainability 2021, 13, 8286. https://doi.org/10.3390/ su13158286

Received: 20 May 2021

Accepted: 21 July 2021

Published: 24 July 2021

Publisher's Note: MDPI stays neutral with regard to jurisdictional claims in published maps and institutional affiliations.

Copyright: (c) 2021 by the authors. Licensee MDPI, Basel, Switzerland. This article is an open access article distributed under the terms and conditions of the Creative Commons Attribution (CC BY) license (https:// creativecommons.org/licenses/by/ $4.0 /)$.

\begin{abstract}
The prevalence of obesity has become a primary risk factor for adolescents' health, which is an essential factor in poverty reduction and sustainable development. Physical activity can help adolescents reduce obesity risk and keep a healthy body mass index (BMI). We analyze the 2010 National Youth Physical Activity and Nutrition Survey (NYPANS) for U.S. school students from 9th to 12th grades (aging from 12 to 18). A latent variable analysis explored the relationship between adolescents' BMI, physical activity, and physical and social environment. We found that Hispanic adolescents have higher BMI because they participate in fewer physical activities. We found that active commuting to school does not provide sufficient physical activity to keep a healthy BMI. The neighborhood environment for physical activity, such as public exercise and recreational center facilities, can reduce BMI but cannot help underweight adolescents increase BMI. Finally, spending too much leisure time on electronic entertainment, such as video games, is a dominating contributor to unhealthy BMI. These research outcomes suggest that providing a physical activity-friendly environment for adolescents, such as the facilities for physical activity in the neighborhood, is critical to a healthy BMI. Interventions that encourage physical activity and reduce leisure time on electronic entertainment to meet physical activity guidelines are also necessary.
\end{abstract}

Keywords: public health; physical activity; physical and social environment; latent variable analysis

\section{Introduction}

The prevalence of childhood obesity has increased markedly in the last three decades [1,2] and has become a severe public health issue in the United States [3,4]. Participating in moderate-vigorous physical activity is a widely recognized sustainable way to make people physically active and has tremendous health benefits [5-7]. The Centers for Disease Control and Prevention's Healthy People 2020 Physical Activity Guidelines recommend that schoolage children participate in three primary types of activities for a minimum of 60-min for three days a week, including aerobic, muscle-strengthening, and bone-strengthening. However, preliminary studies' findings revealed a low proportion of adolescents engaging in 60 min of physical activity daily [8].

Regarding adolescents' lack of physical activity, it is a priority to understand the determinants for promoting physical activity. Adolescents' physical activity usually includes active commuting (e.g., walking and biking) and daily exercises, which have drawn increasing attention in the existing literature on adolescents' health. Adolescents' active commuting to school helps adolescents accumulate daily physical activity and boost their overall physical activity levels [9]. Adolescents that walk or bike to and from school are less likely to be overweight than those that drove or took public transit [10]. Similarly, Banerjee et al. observed the associated benefits of walking to school [11]. Their studies have demonstrated that walking provides the children with a regular dose of physical activity and instills lifelong healthy behaviors. Researchers emphasize the importance of 
teaching children walking habits early on and suggest that commuting to and from school by walking is the best way to achieve this.

Although most of these studies find that active commuting reduces BMI, some suggest that active commuting is weakly associated with BMI or cardiorespiratory fitness [12,13]. The primary reason is that active commuting does not provide sufficient daily physical activity for adolescents $[12,14]$. According to Dellinger, children in the U.S. lived an active life-commuting to school by walking was a part of children's daily routine physical activity five decades ago [15]. However, by adopting less environmentally sustainable modes of transportation, such as driving, the number of children who walk to school has substantially decreased [15]. For example, the percentage of kids walking to school declined from $50 \%$ in the 1960 s to about $15 \%$ in the 2000 s [15]. Thus, as environmentally sustainable modes of transportation, such as active commuting to school, are diminishing among adolescents, the impact of active commuting on adolescents' health becomes debatable. Whether active commuting to school could help adolescents keep healthy BMI needs further exploration.

Since active transportation is not a popular commuting mode to school, adolescents' daily exercise and sports activities become the most critical sources of physical activity, which are suggested to be highly related to children's obesity $[16,17]$. Adolescents' preference for daily exercises or sports activities is primarily determined by social and neighborhood environments, which are related to social and economic sustainability. Social environment mainly refers to their family, such as parents' attitudes to physical activity [18]. Parents with positive attitudes towards an active lifestyle would involve adolescents' in physical activities, increasing adolescents' time engaging in exercise $[19,20]$. Furthermore, the family with a positive attitude to physical activity is likely to pay attention to adolescents' healthy diet [21]. A healthy diet can provide adolescents with the nutrition and energy they need to engage in physical activities [22].

The neighborhood environment primarily influences people's walking behavior, which is an essential source of moderate-vigorous physical activity. Walking is usually associated with a mix of land uses, high-density housing, public transportation frequency, street connectivity, lower-speed limits, low crime, and accessibility to employment opportunities and other destinations [23-25]. Furthermore, neighborhoods with recreational facilities could significantly contribute to a higher level of physical activity and a healthy BMI [26]. Ries et al.'s study suggests that African-American adolescents are likely to use recreational facilities and be physically active when they are affordable and could be accessed by walking [27]. This study also showed that neighborhood facilities availability could help young people avoid drug or gang activities.

On the other hand, the media environment changes make media use a significant risk of adolescents' obesity [28]. In recent years, adolescents rely on multimedia more, and there are emerging studies focusing on the impacts of media use on adolescents' BMI. Long-time sedentary activities such as playing a video game and watching TV take up too much adolescents' leisure time and reduce their time on physical activity [29]. Since the family can control adolescents' media use, parents are encouraged to limit adolescents' time on electronic devices, such as TV, smartphones, and tablets, for adolescents' health [30].

As discussed above, the determinants of both active commuting and regular exercise have been documented in the existing studies. However, few studies have attempted to uncover if physical activities and these social and environmental factors contribute to a healthy BMI for adolescents. In addition, physical activity, such as active commuting to school, does not necessarily contribute to a healthy BMI. Thus, these intertwined relationships between physical activity, children's BMI, and the influenced factors still need further exploration.

The primary objective of this paper is to explore the relationship between adolescents BMI, physical activity, and physical and social environment. We also hope the research outcomes provide implications for the intervention strategies for increasing physical activity and keeping a healthy BMI among adolescents. This research seeks to answer the 
following questions based on this framework: (1) Does active commuting help adolescents keep a healthy BMI? (2) How do neighborhood and social factors influence adolescents' physical activity and BMI? (3) How do these factors influence overweight and underweight adolescents differently?

\section{Data and Methodology}

\subsection{Data Source}

This study is implemented based on the 2010 National Youth Physical Activity and Nutrition Study (NYPANS), a survey containing a 120-item questionnaire. This survey was collected across the U.S. by the Centers for Disease Control and Prevention (CDC). The CDC made these data publicly available to determine if students meet Healthy People 2020 (HP 2020) objectives and inform public policy and decision-making. The data were collected in a three-stage cluster sample design. It is a representative sample, administered in the Spring of 2010 randomly and anonymously to selected public and private high school students aging 12-18 years old. Thus, the fact that the study was administered in the spring is one limitation, as there are socio-cultural behaviors associated with the seasons influencing physical activity. The total number of students that participated in the sample was 11,429 , and the student response rate was $88 \%$ (11,458 of the 12,907 sampled students submit questionnaires). At $82 \%$ (138 of 168 sampled schools participate in this survey), the school response rate was lower. The overall response rate for students was $80 \%$, and 10,277 samples by students were usable after data editing.

This was a self-administered questionnaire taken with premeditated parental permission by students during their regular class period (e.g., at the time of their English, Math class, and so on). Data were collected using a paper-and-pencil questionnaire. A subsample of respondents participated in telephone interviews to measure $24 \mathrm{~h}$ dietary recalls. The CDC trained data collectors who visited the classroom and measured the students' height and weight to determine their BMI using a standard protocol for survey administration-which included taking off coats, shoes, hats, miscellaneous items from pockets, purses, and hair accessories. The scale was cleared to zero, and then the recorded weight was rounded to the nearest pound on an electronic scale on a flat surface without a carpet. A measuring tape was attached to the wall to measure height, and students were asked to stand straight against it. Data collectors recorded the height and weight data on computer scannable booklets linked to each student's survey response. The response rate for this portion of the survey was $80 \%$. Since a total of 1728 participants had missing data on essential items-that is, gender, grade, race, ethnicity, height, weight, or physical activity - these surveys were taken out from the final sample, now at 9701 unique respondents. All the data processing and analysis in this research were implemented following the 1975 Declaration of Helsinki rules.

\subsection{Analytical Framework and Latent Variable Analysis}

Drawing upon the surveying result from NYPANS, this paper implements quantitative analysis to investigate the interrelationship between adolescents' BMI, physical activity, and the physical and social environment. To make these relationships clearer, we develop an analytical framework to explore the relationship between adolescents' BMI, physical activity, and physical and social environment. Figure 1 shows our research based on existing literature. Two major physical activities are included (i.e., active commuting and regular exercise), which are expected to influence adolescents' BMI directly. We consider the determinants of adolescents' physical activity and BMI from six factors, including neighborhood facilities, food intake, daily diet, social support for daily physical activity, feeling about physical activity, and leisure time on media entertainment. Some of these factors are expected to influence BMI, such as food intake and diet directly. Additionally, as the literature suggests, many factors influence adolescents' BMI by changing adolescents' preference for physical activities, such as the facilities for physical activity [27]. So both of the direct and indirect impacts of these variables on adolescents' BMI would be 
fully considered in this framework. A latent variable analysis will reveal the most likely determinants associated with adolescents' BMI and physical activity.
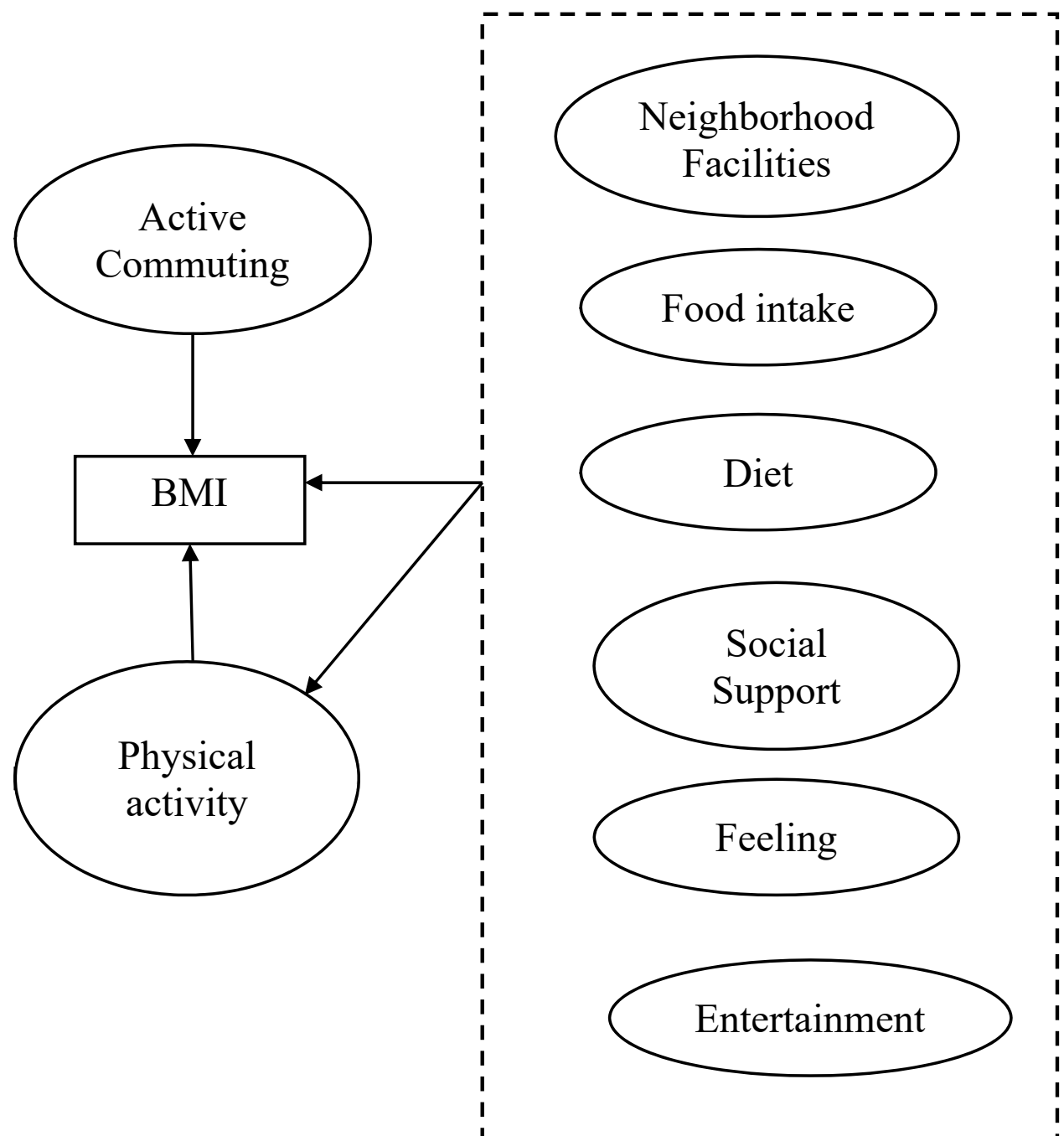

Figure 1. The relationship between children's BMI, physical activity, and the determinants.

The latent variable analysis is employed as an essential technique of the structural equation model, which could reveal the direct and indirect relationship between the variables. The variables included in this study are adolescents' BMI, physical activity, and six latent variables for capturing physical and social environments. The latent variable analysis was constructed based on the framework in Figure 1. The direct and indirect impacts of physical activity and the social and environmental factors on adolescents' BMI are revealed. However, not all social environment factors influence adolescents' physical activity. This study mainly focuses on directly affecting adolescents' BMI and the significant relationship between social and environmental factors and adolescents' physical activity.

The BMI value was calculated by dividing the weight in kilograms by the height in meters. Children's obesity rate is generally determined by the percentile for the teens at the same age. We summarized this survey based on the percentile of BMI values as most literature suggested: the underweight teens (below five percentile), the overweight teens with BMI over 85 percentiles, and the other teens with regular BMI [31-33]. In this study, the teens with BMI below 18 are underweight, and the teens with BMI over 28 are overweight. Regarding the fact that environment and physical activity would have different impacts on underweight adolescents and overweight adolescents, we implemented two additional models separately for underweight adolescents and overweight adolescents. 
Two types of physical activities are included in this survey, active transportation and sports. Active transportation includes walking and biking, while sports were divided into individual and team sports. These data were available for the last seven days. Students were asked to "Please mark on how many of the past days you did this activity." They were also asked to "Think about activities you did before and after school, in the evenings, and on the weekends, by yourself or others." Students were instructed to "Do not include P.E. or gym class. Include activities you did just for fun or in competition." To assess if students met the physical activity recommendations, they were asked a follow-up question, "During the past seven days, on how many days were you physically active for a total of at least 60 min per day?"

The latent variables are derived from the categories of the questions from the survey, and the questions to measure physical and social environment are presented in Table 1. The six latent variables concerning physical and social environment include facilities for physical activity in the neighborhood, feeling about physical activity, support from family, daily diet, food intake, and leisure time on electronic entertainment. This 120-item questionnaire contains all the questions that are related to the variables listed in Table 1. Physical activity is taken as a mediator in the latent variable analysis, while we would like to explore which variables contribute to healthy BMI by promoting physical activity. For example, adolescents' feelings about physical activity and neighborhood environment are suggested to influence people's BMI by changing their preference to participate in physical activities. In addition, several variables concerning adolescents' personal characteristics have been added, including age, gender, grade, and race (Hispanic or not). Although they were not the primary research targets of this paper, the impacts of these variables on adolescents' BMI were still expected to be revealed in the analysis. The structural equation model was employed for the latent variable analysis, revealing direct and indirect associations. We provide a comparative fit index, chi-square, and root mean square error for the good-fitness of the models.

Table 1. The variables used and the abbreviation.

\begin{tabular}{|c|c|c|}
\hline Abbreviations & Questions from the Survey & Data Type (Unit) \\
\hline \multicolumn{3}{|c|}{ Personal Characteristics } \\
\hline Age & Age of the students & Continuous (year) \\
\hline Gender & Gender of the student & "1-female"," 2-male" \\
\hline Grade & Grade of the student & $\begin{array}{l}\text { 1-9th grade; } 2-10 \text { th grade; } \\
3-11 \text { th grade; } 4-12 \text { th grade }\end{array}$ \\
\hline Hispanic & Race of the students (Hispanic or Latino) & $0-$ No, $1-$ Yes \\
\hline \multicolumn{3}{|c|}{ Latent Variable (Physical Activity) } \\
\hline $60 \mathrm{MinPA}$ & $\begin{array}{l}\text { Students are physically active for a total of at least } 60 \\
\text { min yesterday }(1-\text { Yes, } 2-\mathrm{NO})\end{array}$ & 0 -No, $1-Y e s$ \\
\hline 60MinPA2 & $\begin{array}{l}\text { Days that students are physically active for total of at } \\
\text { least } 60 \mathrm{~min} \text { per day during the past } 7 \text { days }\end{array}$ & Continuous (day) \\
\hline 20MinPA & $\begin{array}{l}\text { Days that students exercise or participate in physical } \\
\text { activity for at least } 20 \text { min during the past } 7 \text { days }\end{array}$ & Continuous (day) \\
\hline Exercise & $\begin{array}{l}\text { Days that students do exercises to strengthen or tone } \\
\text { your muscles }\end{array}$ & Continuous (day) \\
\hline \multicolumn{3}{|c|}{ Latent Variable (Electronic Entertainment) } \\
\hline Computer & $\begin{array}{l}\text { Hours on playing video or computer games or using } \\
\text { a computer for something on an average school day }\end{array}$ & Continuous (hour) \\
\hline DVD & $\begin{array}{l}\text { Hours on watching DVDs or videos on an average } \\
\text { school day }\end{array}$ & Continuous (hour) \\
\hline T.V. & Hours on watching T.V. on an average school day & Continuous (hour) \\
\hline \multicolumn{3}{|c|}{ Latent Variable (Commuting to School) } \\
\hline BikeTo & $\begin{array}{c}\text { Days that students walk or ride bike to school in an } \\
\text { average week when you are in school }\end{array}$ & Continuous (day) \\
\hline BikeFrom & $\begin{array}{l}\text { Days that students walk or ride bike home from } \\
\text { school in an average week when you are in school }\end{array}$ & Continuous (day) \\
\hline
\end{tabular}


Table 1. Cont.

\begin{tabular}{|c|c|c|}
\hline Abbreviations & Questions from the Survey & Data Type (Unit) \\
\hline \multicolumn{3}{|c|}{ Latent Variable (Feeling About Physical Activity) } \\
\hline $\begin{array}{l}\text { PAenjoy } \\
\text { PAfun } \\
\text { PAenergy } \\
\text { PAgood } \\
\text { PAsuccess }\end{array}$ & $\begin{array}{l}\text { When I am physically active, I enjoy it. } \\
\text { When I am physically active, I find it fun. } \\
\text { When I am physically active, It gives me energy. } \\
\text { When I am physically active, My body feels good. } \\
\text { When I am physically active, it gives me a strong } \\
\text { feeling of success. }\end{array}$ & $\begin{array}{l}\text { 1-Strongly disagree; } 2 \text {-disagree; } \\
\text { 3-Neither Agree nor disagree; } \\
\text { 4-agree; 5-Strongly agree }\end{array}$ \\
\hline \multicolumn{3}{|c|}{ Latent Variable (Facilities for Physical Activity in the Neighborhood) } \\
\hline $\begin{array}{l}\text { Sportquip } \\
\text { Park } \\
\text { Safe }\end{array}$ & $\begin{array}{l}\text { There are enough pieces of sports equipment to use } \\
\text { for physical activity at home ( } 1-\text { Yes, } 2-\mathrm{NO}) \\
\text { There are playgrounds, parks, or gyms close to my } \\
\text { home that are easy for me to get to (1-Yes, } 2-\mathrm{NO}) \\
\text { It is safe to be physically active by myself in my } \\
\text { neighborhood (1-Yes, } 2-\mathrm{NO})\end{array}$ & 0 -No, 1 -Yes \\
\hline \multicolumn{3}{|c|}{ Latent Variable (Support from Family on Physical Activity) } \\
\hline Transport & $\begin{array}{c}\text { Frequency that an adult in your household, } \\
\text { encourage you to do physical activities or play sport } \\
\text { during a typical week } \\
\text { Frequency that an adult in your household, do } \\
\text { activity or play sports with you during a typical } \\
\text { week } \\
\text { Frequency that an adult in your household, provide } \\
\text { transportation to a place where you can do physical } \\
\text { activity during a typical week } \\
\text { Frequency that an adult in your household, watch } \\
\text { you participate in physical activities or sport during } \\
\text { a typical week }\end{array}$ & $\begin{array}{l}\text { 1-Never; } 2-1 \text { or } 2 \text { times week; } \\
3-2 \text { or } 3 \text { times a week; } 4-3 \text { or } 4 \\
\text { times a week; } 5 \text {-daily }\end{array}$ \\
\hline \multicolumn{3}{|c|}{ Latent Variable (Healthy Diet) } \\
\hline $\begin{array}{l}\text { Breakfast } \\
\text { Lunch } \\
\text { 5+fruit } \\
\text { 3+fruit }\end{array}$ & $\begin{array}{l}\text { Days that students eat breakfast in past } 7 \text { days } \\
\text { Days that students eat lunch in past } 7 \text { days } \\
\text { Ate } 5+\text { fruits/vegetables/day } 7 \text { days (1-Yes, } \\
\text { 2-NO) } \\
\text { Ate } 3+\text { vegetables/day } 7 \text { days (1-Yes, } 2-\mathrm{NO})\end{array}$ & $\begin{array}{c}\text { Continuous (day) } \\
\text { Continuous (day) } \\
0-\mathrm{NO}, 1-\text { Yes } \\
0-\mathrm{NO}, 1-\text { Yes }\end{array}$ \\
\hline \multicolumn{3}{|c|}{ Latent variable (Food Intake) } \\
\hline Fries & $\begin{array}{l}\text { Frequency that students eat french fries or other } \\
\text { fried potatoes in past } 7 \text { days }\end{array}$ & Continuous (time) \\
\hline Pizza & Frequency that students eat pizza in past 7 days & Continuous (time) \\
\hline Soda & $\begin{array}{l}\text { Frequency that students drink a can, bottle, or glass } \\
\text { of soda in past } 7 \text { days }\end{array}$ & Continuous (time) \\
\hline Coffee & $\begin{array}{l}\text { Frequency that students drink a cup, can or bottle of } \\
\text { coffee, coffee drinks, or any kind of tea in past } 7 \text { days }\end{array}$ & Continuous (time) \\
\hline Milk & The glasses of milk students drink in past 7 days & Continuous (glass) \\
\hline
\end{tabular}

\subsection{Statistical Analysis}

The samples in this study include both underweight and overweight adolescents. To verify the differences between children's BMI values in different groups, we implement a T-test to test both variance and mean. The significant levels are indicated by the $p$-value for all the analyses. The T-test results suggest significant differences between the variance and mean values of these three groups ( $p$-value $<0.01$ ). The statistical results include the mean values for continuous variables and the count values for categorical variables. The means values of the continuous variables would be presented with standard deviation, and the count variables would be presented as the percentage of the total samples. We also use a T-test to compare the mean values of adolescents' physical and neighborhood factors in different groups and the significances. The software in Rstudio (RStudio Public-benefit corporation, Vienna, Austria) with R language version 3.6.3 was used to perform all the statistical methods, including the T-test and the latent variable analysis. 


\section{Results}

\subsection{Statistical Results}

According to the statistical results in Table 2, we find that about $32 \%$ of the obese and $28 \%$ of the underweight adolescents are Hispanic, close to $30 \%$, which is the total sample rate. There is no significant gap in healthy BMI between Hispanic and non-Hispanic adolescents. Similar results could be found for gender as the female is only one percent higher than the average. Thus, personal characteristics are not the dominating factors that influence adolescents' BMI, and the gaps caused by race and gender are closing.

Table 2. Statistical results of the survey questions.

\begin{tabular}{|c|c|c|c|c|}
\hline Abbreviations & Category & $\begin{array}{l}\text { Underweight } \\
\text { (BMI } \leq 18)\end{array}$ & $\begin{array}{l}\text { Regular Weight } \\
(18<\mathrm{BMI}<28)\end{array}$ & $\begin{array}{l}\text { Overweight } \\
\text { (BMI < 28) }\end{array}$ \\
\hline Total number & & $640(8 \%)$ & $6035(72 \%)$ & $1664(20 \%)$ \\
\hline \multicolumn{5}{|c|}{ Personal characteristics } \\
\hline Age & & $15.71(1.23)^{* * *}$ & $16.11(1.21)$ & $16.35(1.20)^{* * *}$ \\
\hline \multirow{2}{*}{ Gender } & Male & $308(48 \%)$ & $3019(50 \%)$ & $826(50 \%)$ \\
\hline & Female & $332(52 \%)$ & $3016(50 \%)$ & $838(48 \%)$ \\
\hline Grade & & $2.15(1.13)$ & $2.46(1.11)$ & $2.62(1.11)$ \\
\hline \multirow{2}{*}{ Hispanic } & Hispanic & $191(29 \%)$ & $1787(30 \%)$ & $537(32 \%)$ \\
\hline & Other & $449(71 \%)$ & $4246(70 \%)$ & $1127(68 \%)$ \\
\hline \multicolumn{5}{|c|}{ Physical activity } \\
\hline \multirow{2}{*}{60 Min PA } & Yes & $375(59 \%)$ & $3751(62 \%)$ & $980(58 \%)$ \\
\hline & NO & $265(41 \%)$ & $2284(38 \%)$ & $684(42 \%)$ \\
\hline 60 Min PA2 & & $2.75(1.87)^{* * *}$ & $4.25(1.85)$ & $3.89(1.79)^{* * *}$ \\
\hline 20 Min PA & & $3.36(2.27)^{* * *}$ & $4.89(2.23)^{* * *}$ & $4.51(2.11)^{* * *}$ \\
\hline Exercise & & $2.57(2.24)^{* * *}$ & $3.85(2.30)^{* * *}$ & $3.46(2.23) * * *$ \\
\hline \multicolumn{5}{|c|}{ Electronic entertainment } \\
\hline Computer & & $3.58(1.69)^{* * *}$ & $3.32(1.66)$ & $3.42(1.73)$ \\
\hline DVD & & $3.10(1.83)$ & $3.21(1.85)$ & $3.41(1.84)^{* * *}$ \\
\hline $\mathrm{TV}$ & & $3.70(1.64)$ & $3.70(1.75)$ & $3.97(1.74)^{* * *}$ \\
\hline \multicolumn{5}{|c|}{ Feeling about physical activity } \\
\hline PAenjoy & & $4.17(0.87)$ & $4.26(0.89)$ & $4.11(0.89)^{* * *}$ \\
\hline PAfun & & $4.08(0.88)$ & $4.15(0.94)$ & $4.01(0.92) * * *$ \\
\hline PAenergy & & $3.9(1.07)^{* * *}$ & $4.10(1.05)$ & $4.00(1.03)^{* * *}$ \\
\hline PAgood & & $4.02(1.03)^{* * *}$ & $4.17(1.03)$ & $4.01(1.05)^{* * *}$ \\
\hline PAsuccess & & $4.05(1.04)^{* * *}$ & $4.20(1.02)$ & $4.13(1.00) * * *$ \\
\hline \multicolumn{5}{|c|}{ Facilities for Physical Activity in the Neighborhood } \\
\hline Sportquip & & $3.85(1.23)$ & $3.84(1.26)$ & $3.57(1.34)^{* * *}$ \\
\hline Park & & $3.74(1.32)$ & $3.80(1.35)$ & $3.60(1.38) * * *$ \\
\hline Safe & & $3.87(1.15)$ & $3.95(1.17)$ & $3.75(1.21)^{* * *}$ \\
\hline \multicolumn{5}{|c|}{ Support from family } \\
\hline Encourage & & $2.67(1.48)$ & $2.80(1.54)$ & $2.77(1.48)$ \\
\hline Playwith & & $1.80(1.10)$ & 1.88 (1.17) & $1.86(1.20)$ \\
\hline Transport & & $2.56(1.55)^{* * *}$ & $2.81(1.61)$ & $2.50(1.55)^{* * *}$ \\
\hline Watch & & $2.23(1.39)^{* * *}$ & $2.42(1.49)$ & $2.224(1.43)^{* * *}$ \\
\hline \multicolumn{5}{|c|}{ Healthy Diet } \\
\hline Breakfast & & $5.49(2.57)$ & $5.31(2.58)$ & $4.77(2.61)^{* * *}$ \\
\hline Lunch & & $6.92(1.83)$ & $6.78(1.94)$ & $6.32(2.11)^{* * *}$ \\
\hline \multirow{2}{*}{ 5+fruit } & Yes & $173(27 \%)$ & $1642(27 \%)$ & $480(29 \%)$ \\
\hline & $\mathrm{NO}$ & $467(73 \%)$ & $4391(73 \%)$ & $1184(71 \%)$ \\
\hline \multirow{2}{*}{$3+$ fruit } & Yes & $108(17 \%)$ & $1068(18 \%)$ & $324(19 \%)$ \\
\hline & $\mathrm{NO}$ & $532(83 \%)$ & $4965(82 \%)$ & $1340(81 \%)$ \\
\hline
\end{tabular}


Table 2. Cont.

\begin{tabular}{|c|c|c|c|c|}
\hline Abbreviations & Category & $\begin{array}{l}\text { Underweight } \\
\text { (BMI } \leq 18)\end{array}$ & $\begin{array}{l}\text { Regular Weight } \\
(18<\text { BMI < 28) }\end{array}$ & $\begin{array}{l}\text { Overweight } \\
\text { (BMI < 28) }\end{array}$ \\
\hline \multicolumn{5}{|c|}{ Food Intake } \\
\hline Fries & & $2.33(1.20)$ & $2.27(1.17)$ & $2.17(1.08) * * *$ \\
\hline Pizza & & $2.08(1.05)$ & $2.03(1.06)$ & $1.97(1.06)$ \\
\hline Soda & & $2.91(1.68)$ & $2.71(1.68)$ & $2.73(1.69) * * *$ \\
\hline Coffee & & $2.04(1.38)$ & $2.05(1.40)$ & $2.08(1.42)$ \\
\hline Milk & & 3.17 (1.73) & $3.14(1.75)$ & 3.09 (1.73) \\
\hline \multicolumn{5}{|c|}{ Active commuting } \\
\hline BikeTo & & $1.81(1.73)$ & $1.72(1.78)$ & $1.81(1.81)$ \\
\hline BikeFrom & & $2.03(1.87)$ & $1.94(1.78)$ & $2.03(1.87)$ \\
\hline
\end{tabular}

Note: ${ }^{* * *}$ Significant at 0.01 level. Abbreviations for the variables are available in Table 1.

Regarding the physical activity variables, active commuting to school is not in itself a promising physical activity because Table 2 suggests that adolescents who frequently walk or bike to school do not necessarily have a healthier BMI. Table 2 also indicates that both underweight and overweight teens are not physically active from the perspective of HP 2020 guidelines compared to healthy teens. Underweight teens' lacking physical activity is more significant than overweight teens, highlighting the importance of promoting underweight teens' physical activity. Furthermore, the mean values of the variables for physical activities are below five, suggesting that most adolescents do not engage in the recommended 60 min of exercise every day by HP 2020.

According to the statistical results, adolescents with positive attitudes to physical activity and supported by their parents are likely to maintain a healthy BMI. Inadequate facilities for physical activity in the neighborhood might be a cause of adolescents' obesity. Spending too much leisure time on electronic entertainment may contribute to obesity as well. Additionally, the underweight teens usually spend more time on the computer than others.

Although we briefly summarize the physical and social environment variables, these relationships are not entirely clear. The statistical results could not reveal the impacts of other factors on BMI or physical activity. Thus, we used a structural equation modeling method to investigate the interaction between these variables.

\subsection{Latent Variable Analysis}

The result of the latent variable analysis is presented in Figure 2. The arrows represent the direct relationship between the variables. There is no significant direct relationship between Hispanic adolescents and the high value of BMIs. However, the model suggests that Hispanic teens are likely to participate in less physical activity than others, which gives them a higher risk of obesity. Lacking physical activity could be a reason that some of the Hispanic teens present with unhealthy BMIs.

Two latent variables concerning exercise were employed in this study: regular physical activity and active commuting to school. Although it has been well documented in the literature that active commuting could be a regular moderate to vigorous physical activity for adolescents, the model results suggest that walking or biking to school is not associated with BMI in this series of adolescents. The primary reason may be that walking or biking to school is not the dominating commuting mode for adolescents, while the average frequency is about 2.5 per week. 


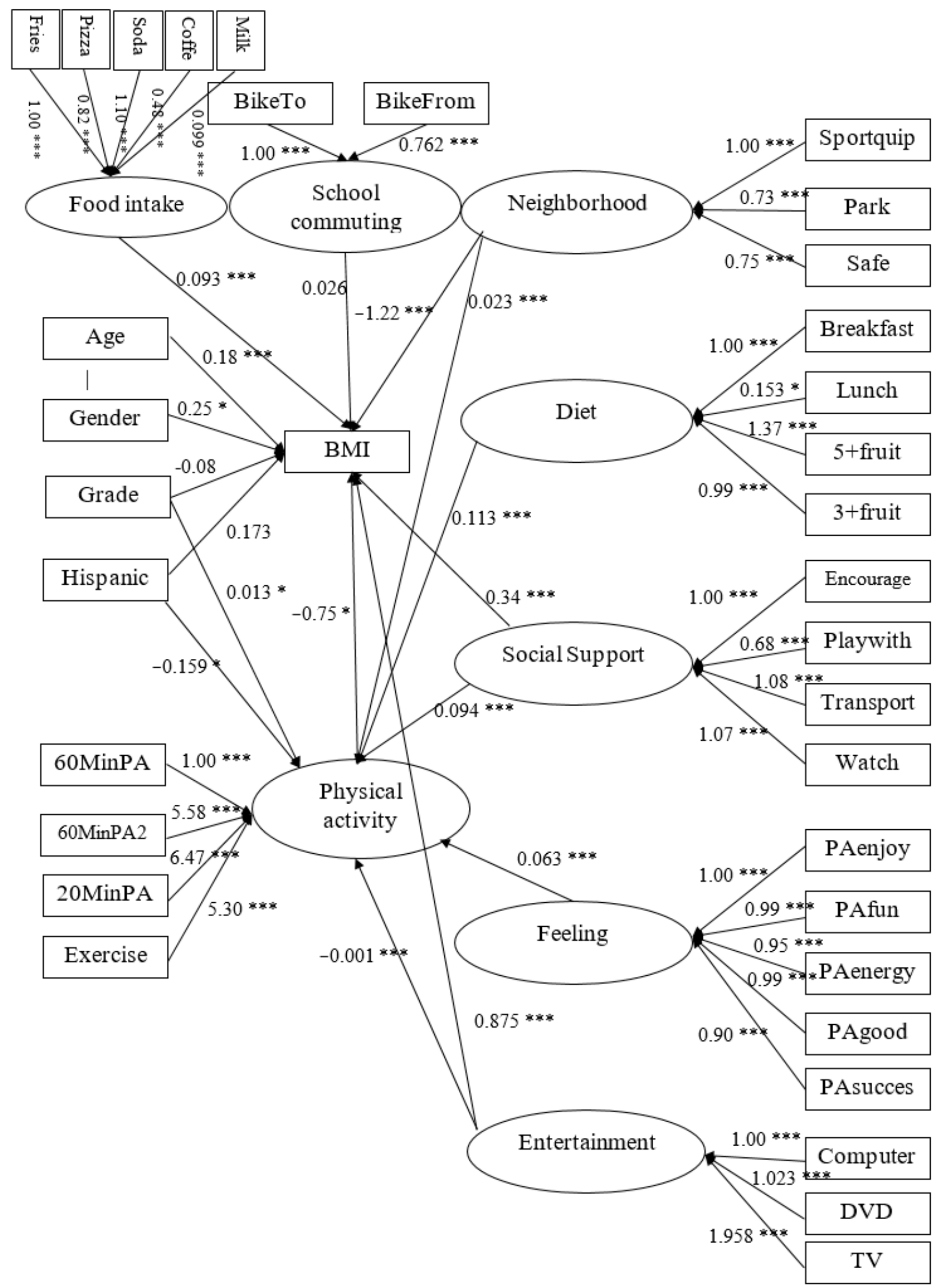

Figure 2. The result of latent variable analysis. Note: * Significant at 0.1 level, *** Significant at 0.01 level. Abbreviations for the variables are available in Table 1. 
Regarding other variables. The physical activity facility consists of three questions that concern sports equipment, playgrounds, and neighborhood safety. The results suggest that physical activity facilities may be directly associated with a healthier BMI by promoting adolescents' physical activity. Support from family on physical activity makes adolescents physically active and helps keep a healthy BMI. According to the model results, adults staying at home and assisting teens in participating in physical activities would be associated with a better BMI in adolescents.

This survey contains four questions about a healthy diet, including eating breakfast, lunch, fruits, and vegetables. The model results suggest that a healthy daily diet may indirectly contribute to more physical activities and adequate BMI. Diet is positively related to students' feelings, which could explain that a healthy diet makes youth feel energetic to take part in physical activities. We also consider some other food intake such as fries and soda in this model, which are not very healthy. However, the model results manifest the fact that intakes of fries and soda is associated with a lower adolescents' BMI.

The model result further shows that adolescents' leisure time on electronic entertainment is considered a risk factor for obesity. According to the NYPANS, adolescents would spend about three hours on video, computers, or TV during the school day. Furthermore, we found that leisure time on electronic entertainment has only a small impact on physical activity. Thus, electronic entertainment may influence BMI because adolescents sit for a long time rather than reduce regular physical activity.

Table 3 summarizes the direct, indirect, and total associations between these variables and adolescents' BMI. Although all the other latent variables may contribute to a higher preference to participate in physical activities, they do not all help reduce BMI. The total associations in Table 3 suggest that teens with more support from family for physical activity even have a higher BMI value. Adolescents' leisure time on electronic entertainment significantly contributes to higher BMI. The latent variable, support from family, has positive direct associations (coefficient 0.351) and meager negative indirect associations (coefficient -0.007 ) on adolescents' BMI. Regarding the total associations, adolescents who do not receive family support for physical activity would have a higher BMI

Table 3. Direct, indirect, and total associations of the latent variables on BMI using physical activity as a latent mediator.

\begin{tabular}{|c|c|c|c|}
\hline & Direct Association & Indirect Association & Total Association \\
\hline Neighborhood & $-1.22 * * *$ & $-0.017^{* * *}$ & $-1.24^{* * *}$ \\
\hline Food Intake & $-0.93^{* * *}$ & / & $-0.93^{* * *}$ \\
\hline Diet & 0.097 & $-0.047^{*}$ & 0.11 \\
\hline Support from family & $0.351 * * *$ & $-0.07^{*}$ & $0.281^{* * *}$ \\
\hline Feeling & 0.097 & $-0.047^{*}$ & 0.051 \\
\hline Active commuting & 0.026 & / & 0.026 \\
\hline Entertainment & $0.875^{* * *}$ & $0.001^{* * *}$ & $0.876^{* * *}$ \\
\hline \multicolumn{4}{|c|}{ Model good-fitness } \\
\hline $\begin{array}{l}\text { Comparative Fit } \\
\text { Index }\end{array}$ & & 0.884 & \\
\hline$p$-value for Chi-squre & & 0.000 & \\
\hline $\begin{array}{l}p \text {-value for root mean } \\
\text { squre error }(\mathrm{RMSE}) \\
\leq 0.05\end{array}$ & & 1.000 & \\
\hline
\end{tabular}

\subsection{A Pooled Latent Variable Analysis}

In this study, the healthy BMI for adolescents ranges from 18 to 28 according to their nutritional status by BMI. The overweight teens' and underweight teens' BMI might be influenced by different variables, which create heterogeneity. Thus, we implemented two pooled models separately for overweight adolescents and underweight adolescents, which 
follow the latent variable analysis above. The direct association, indirect association, and total association are presented in Tables 4 and 5.

Table 4. The latent variable analysis for overweight teens.

\begin{tabular}{|c|c|c|c|}
\hline & Direct Association & Indirect Association & Total Association \\
\hline Age & / & / & $0.589^{* * *}$ \\
\hline Gender & / & / & -0.095 \\
\hline Grade & / & / & -0.344 \\
\hline Hispanic & / & / & -0.61 * \\
\hline Physical activity & -0.462 & / & -0.462 \\
\hline Neighborhood & $-0.842^{* * *}$ & -0.018 & $-0.895^{* * *}$ \\
\hline Food intake & -0.019 & / & -0.019 \\
\hline Diet & $-1.443 *$ & -0.032 & $-1.522 * *$ \\
\hline Social support & 0.189 & -0.038 & 0.151 \\
\hline Feeling & $-0.358 *$ & -0.032 & $-0.39 *$ \\
\hline Active commuting & -0.023 & / & -0.023 \\
\hline Entertainment & $0.733^{* * *}$ & 0.008 & $0.741^{* * *}$ \\
\hline \multicolumn{4}{|c|}{ Model good-fitness } \\
\hline $\begin{array}{l}\text { Comparative Fit } \\
\text { Index }\end{array}$ & & 0.885 & \\
\hline $\begin{array}{l}p \text {-value for } \\
\text { Chi-square }\end{array}$ & & 0.000 & \\
\hline $\begin{array}{l}p \text {-value for root mean } \\
\text { square error (RMSE) } \\
\quad \leq 0.05\end{array}$ & & 1.000 & \\
\hline
\end{tabular}

Table 5. The latent variable analysis for underweight teens.

\begin{tabular}{|c|c|c|c|}
\hline & Direct Association & Indirect Association & Total Association \\
\hline Age & / & / & 0.051 \\
\hline Gender & / & / & 0.068 \\
\hline Grade & / & / & -0.092 \\
\hline Hispanic & / & / & $-0.146^{*}$ \\
\hline Physical activity & -0.256 & / & -0.256 \\
\hline Neighborhood & -0.047 & 0.006 & -0.041 \\
\hline Food intake & 0.087 & / & / \\
\hline Diet & -0.077 & -0.003 & -0.08 \\
\hline Social support & -0.001 & -0.027 & -0.029 \\
\hline Feeling & 0.107 & -0.029 & 0.077 \\
\hline Active commuting & 0.011 & / & 0.011 \\
\hline Entertainment & 0.138 & 0.011 & 0.149 \\
\hline \multicolumn{4}{|c|}{ Model good-fitness } \\
\hline $\begin{array}{l}\text { Comparative Fit } \\
\text { Index }\end{array}$ & & 0.878 & \\
\hline $\begin{array}{l}p \text {-value for } \\
\text { Chi-square }\end{array}$ & & 0.000 & \\
\hline $\begin{array}{l}p \text {-value for root mean } \\
\text { square error (RMSE) } \\
\leq 0.05\end{array}$ & & 0.787 & \\
\hline
\end{tabular}

The model coefficients in Table 4 suggest that proximity to a playground or public park would contribute to a lower value of BMI for overweight adolescents. Adolescents' positive attitudes towards physical activity may help maintain healthy BMI because they have an awareness of the benefit of exercise. Physical activity should not be an irrelevant factor in overweight adolescents' BMI regarding these variables' associations. According to 
this model, only 60 min of physical activity for four days a week does not help overweight adolescents to achieve a healthy BMI.

For underweight adolescents, Hispanic teens are likely to have a lower value of BMI. However, the other physical activity and environment variables are not associated with the underweight adolescents' BMI. Additionally, the model good-fitness indices show that the model in Table 5 does not fit very well for underweight teens. Thus, this framework does not help find determinants associated with the BMI of underweight adolescents. It is also notable that food intake is not significant in both of these two tables, suggesting that food intake only influences regular adolescents' BMI.

\section{Discussion}

This study primarily tries to answer the research questions concerning adolescents' BMI, active commuting and regular physical activity, and physical and social environments. The result of latent variable analysis suggests that active commuting to schools, such as walking or biking, cannot help adolescents keep a healthy BMI. A significant reason is that active commuting is not a popular transportation mode to school among adolescents [14]. The trend that people in the U.S. rely on the automobile for commuting cannot be reversed, making it challenging to promote active commuting to school. Thus, active commuting to school should not be considered as the major source of adolescents' physical activity, and other types of exercise should be promoted.

The facilities for physical activity in the neighborhood and family support could help promote physical activity and decrease BMI. Existing literature mainly focuses on the associations of urban design with people's walking behavior [23-25]. Future studies should pay more attention to the impact of neighborhood amenities, such as public facilities and green space. Furthermore, the model results suggest that family support for physical activity is negatively associated with physical activity. There is a negative association between the facility for physical activity in the neighborhood and family support for physical activity. Lacking the facilities for physical activity in the neighborhood could motivate families to provide support for the physical activity of the adolescent.

A healthy diet and positive feelings about exercising may contribute to more adolescents' physical activity but are not highly associated with adolescents' BMI. It is interesting to see that the intake of some unhealthy foods, such as fries and coffee, even may reduce adolescents' BMI, as suggested in Table 3. Further analysis manifests the fact that these food intakes are only associated with adolescents with regular BMI. Since some unhealthy foods, such as fries, have become more and more common in adolescents' daily life, it becomes more difficult to investigate their negative impact. Compared to the significant association of neighborhood and family environment, the association between food environment and adolescents' BMI is not significant enough.

Furthermore, media use is suggested to contribute to adolescents' obesity by decreasing physical activity [29]. However, our research outcomes indicate that adolescents' leisure time on electronic entertainment is most associated with higher BMI directly but has few associations with physical activity. Adolescents' leisure time might increase BMI because adolescents sit for a long time rather than engaging in physical activity.

On the other hand, the facilities for physical activity in the neighborhood, a healthy diet, and a positive attitude to physical activity can help relieve adolescents' overweight problems. However, physical activity is still not associated with overweight adolescents' BMI, and the factors above do not contribute to more physical activity. We assume that the survey questions, including $20 \mathrm{~min}$ or $60 \mathrm{~min}$ physical activity, are not enough for overweight adolescents. This makes us think that schools should set higher goals (e.g., $90 \mathrm{~min}$ per day instead of $60 \mathrm{~min}$ ) to achieve the recommended times for physical activity to keep a healthy weight. For example, in Canada, the adolescent physical activity guidelines were changed from 60 to 90 min daily [31].

Our research also finds that underweight and overweight adolescents' BMIs are associated with different factors. The social and neighborhood environment factors are not 
associated with underweight adolescents' BMI. Thus, the strategy to help underweight adolescents should include factors beyond this study. Although being underweight is not a significant challenge that the adolescent in the U.S. is facing, determinants of underweight adolescents' BMI are also worthy of further investigations. Different environmental factors influence the underweight, overweight, and normal adolescents' BMIs according to the pooled latent variable analysis. Therefore, further exploration should consider this heterogeneity among different adolescent groups.

Limitations still exist in the survey, such as less emphasis on ignoring the social and cultural factors, which are also important determinants of people's physical activity and health. A more comprehensive survey could better understand physical activity promotion and keeping a healthy BMI. Additionally, this survey is implemented in spring. The season would influence adolescents' preference to perform physical activity, and a dataset for all seasons would help strengthen our results. Furthermore, this study used a dataset in 2010, and a more recent dataset could provide more information about the change in recent years.

\section{Conclusions}

Based on the NYPANS data and statistical analysis results, it is concluded that physical activity might be the dominating influencing factor of adolescents' BMI, and lack of physical activity is a high-risk factor for adolescents to have unhealthy BMIs. On the other hand, adolescents' active commuting to school has few associations with BMI because active commuting is not popular now and cannot provide enough physical activity for adolescents. Neighborhood facilities and family support for physical activity have positive associations. The leisure time on electronic entertainment might contribute to higher adolescents' BMI because adolescents sit for a long time while watching TV or playing video games rather than doing physical activity. Thus, physical and social neighborhood environment was significantly associated with adolescents' BMI. These research outcomes help conclude that environmental factors are critical to reducing the obesity epidemic in the U.S. Regarding the underweight adolescents' BMI, both the physical and social environmental factors and physical activity have little association.

Author Contributions: Conceptualization, Y.D.W. and W.X.; Methodology and software, W.X.; Writing-review and editing, Y.D.W., W.X. and I.G. All authors have read and agreed to the published version of the manuscript.

Funding: This research received no external funding.

Institutional Review Board Statement: Not applicable.

Informed Consent Statement: Not applicable.

Data Availability Statement: Data available on request due to restrictions eg privacy or ethical.

Conflicts of Interest: The authors declare no conflict of interest.

\section{References}

1. Ogden, C.L. Obesity and Socioeconomic Status in Children and Adolescents: United States, 2005-2008; (No. 51); U.S. Department of Health and Human Services, Centers for Disease Control and Prevention, National Center for Health Statistics: Hyattsville, MD, USA, 2010.

2. Wang, Y.; Gortmaker, S.L.; Taveras, E.M. Trends and racial/ethnic disparities in severe obesity among U.S. children and ado-lescents, 1976-2006. Int. J. Pediatric Obes. 2010, 6, 12-20. [CrossRef]

3. Wang, Y.; Zhang, Q. Are American children and adolescents of low socioeconomic status at increased risk of obesity? Am. J. Clin. Nutr. 2006, 84, 707-716. [CrossRef] [PubMed]

4. Wang, Y.; Beydoun, M.A. The obesity epidemic in the United States-Gender, age, socioeconomic, racial/ethnic, and geo-graphic characteristics. Epidemiol. Rev. 2007, 29, 6-28. [CrossRef] [PubMed]

5. $\quad$ Reichert, F.F.; Menezes, A.M.B.; Wells, J.C.; Dumith, S.C.; Hallal, P.C. Physical activity as a predictor of adolescent body fat-ness. Sports Med. 2009, 39, 279-294. [CrossRef] 
6. Mansikkaniemi, K.; Juonala, M.; Taimela, S.; Hirvensalo, M.; Telama, R.; Huupponen, R.; Jula, A. Cross-sectional associa-tions between physical activity and selected coronary heart disease risk factors in young adults. Ann. Med. 2012, 44, 733-744. [CrossRef] [PubMed]

7. Timperio, A.; Ball, K.; Salmon, J.; Roberts, R.; Giles-Corti, B.; Simmons, D.; Crawford, D. Personal, family, social, and environmental correlates of active commuting to school. Am. J. Prev. Med. 2006, 30, 45-51. [CrossRef] [PubMed]

8. Vigo-Valentín, A.; Hodge, S.R.; Kozub, F.M. Adolescents' dietary habits, physical activity patterns, and weight status in Puerto Rico. Child. Obes. 2011, 7, 488-494. [CrossRef]

9. Cooper, A.R.; Andersen, L.B.; Wedderkopp, N.; Page, A.S.; Froberg, K. Physical activity levels of children who walk, cycle, or are driven to school. Am. J. Prev. Med. 2005, 29, 179-184. [CrossRef] [PubMed]

10. Arango, C.M.; Parra, D.C.; Eyler, A.; Sarmiento, O.; Mantilla, S.C.; Gomez, L.F.; Lobelo, F. Walking or bicycling to school and weight status among adolescents from Montería, Colombia. J. Phys. Act. Health 2011, 8, S171-S177. [CrossRef]

11. Banerjee, T.; Uhm, J.; Bahl, D. Walking to school. J. Plan. Educ. Res. 2014, 34, 123-140. [CrossRef]

12. Lee, M.C.; Orenstein, M.R.; Richardson, M.J. Systematic review of active commuting to school and children's physical activity and weight. J. Phys. Act. Health 2008, 5, 930-949. [CrossRef] [PubMed]

13. Muntaner-Mas, A.; Herrador-Colmenero, M.; Borràs, P.A.; Chillón, P. Physical activity, but not active commuting to school, is associated with cardiorespiratory fitness levels in young people. J. Transp. Health 2018, 10, 297-303. [CrossRef]

14. Heelan, K.A.; Donnelly, J.E.; Jacobsen, D.J.; Mayo, M.S.; Washburn, R.; Greene, L. Active commuting to and from school and BMI in elementary school children-preliminary data. Child 2005, 31, 341-349. [CrossRef] [PubMed]

15. Dellinger, A.M. Centers for Disease Control and Prevention. Barriers to children walking and biking to school—United States, 1999. Morb. Mortal. Wkly. Rep. 2002, 51, 701-704.

16. Nqweniso, S.; Walter, C.; du Randt, R.; Aerts, A.; Adams, L.; Degen, J.; Gerber, M. Prevention of Overweight and Hypertension through Cardiorespiratory Fitness and Extracurricular Sport Participation among South African Schoolchildren. Sustainability 2020, 12, 6581. [CrossRef]

17. Pyšná, J.; Pyšný, L.; Cihlář, D.; Petrů, D.; Škopek, M. Effect of Physical Activity on Obesity in Second Stage Pupils of Elementary Schools in Northwest Bohemia. Sustainability 2020, 12, 10042. [CrossRef]

18. Ornelas, I.J.; Perreira, K.M.; Ayala, G.X. Parental influences on adolescent physical activity. Int. J. Behav. Nutr. Phys. Act. 2007, 4, 3. [CrossRef]

19. O'Connor, T.M.; Jago, R.; Baranowski, T. Engaging parents to increase youth physical activity: A systematic review. Am. J. Prev. Med. 2009, 37, 141-149. [CrossRef]

20. Espinoza-Salinas, A.; Molina-Sotomayor, E.; Cano-Montoya, J.; Gonzalez-Jurado, J.A. Is Active Lifestyle Related to Autonomic Nervous System Function and Lipid Profile in People with Overweight? A Study Pilot. Sustainability 2021, 13, 2439. [CrossRef]

21. Sallis, J.F.; Prochaska, J.J.; Taylor, W.C. A review of correlates of physical activity of children and adolescents. Med. Sci. Sports Exerc. 2000, 32, 963-975. [CrossRef]

22. Sabiston, C.M.; Crocker, P.R. Examining an integrative model of physical activity and healthy eating self-perceptions and behaviors among adolescents. J. Adolesc. Health 2008, 42, 64-72. [CrossRef] [PubMed]

23. Ewing, R.; Cervero, R. Travel and the build environment: A synthesis. Transp. Res. Rec. 2001, 1780, 87-114. [CrossRef]

24. Heath, G.W.; Brownson, R.C.; Kruger, J.; Miles, R.; Powell, K.E.; Ramsey, L.T. The effectiveness of urban design and land use and transport policies and practices to increase physical activity: A systematic review. J. Phys. Act. Health 2006, 3, S55-S76. [CrossRef]

25. Wei, Y.D.; Xiao, W.; Medina, R.; Tian, G. Effects of neighborhood environment, safety, and urban amenities on origins and destinations of walking behavior. Urban Geogr. 2021, 42, 120-140. [CrossRef]

26. Norman, G.J.; Nutter, S.K.; Ryan, S.; Sallis, J.F.; Calfas, K.J.; Patrick, K. Community design and access to recreational facili-ties as correlates of adolescent physical activity and body-mass index. J. Phys. Act. Health 2006, 3, S118-S128. [CrossRef]

27. Ries, A.V.; Gittelsohn, J.; Voorhees, C.C.; Roche, K.M.; Clifton, K.J.; Astone, N.M. The environment and urban adolescents' use of recreational facilities for physical activity: A qualitative study. Am. J. Health Promot. 2008, 23, 43-50. [CrossRef]

28. Jordan, A.B.; Kramer-Golinkoff, E.K.; Strasburger, V.C. Does adolescent media use cause obesity and eating disorders. Adolesc. Med. State Art Rev. 2008, 19, 431-449.

29. Vandewater, E.A.; Shim, M.S.; Caplovitz, A.G. Linking obesity and activity level with children's television and video game use. J. Adolesc. 2004, 27, 71-85. [CrossRef] [PubMed]

30. Kenney, E.L.; Gortmaker, S.L. United States adolescents' television, computer, videogame, smartphone, and tablet use. J. Pediatr 2017, 182, 144-149. [CrossRef]

31. Aaron, D.J.; Storti, K.L.; Robertson, R.J.; Kriska, A.M.; LaPorte, R.E. Longitudinal study of the number and choice of leisure time physical activities from mid to late adolescence: Implications for school curricula and community recreation programs. Arch. Pediatr. Adolesc. Med. 2002, 156, 1075-1080. [CrossRef]

32. Guo, S.S.; Wu, W.; Chumlea, W.C.; Roche, A.F. Predicting overweight and obesity in adulthood from body mass index values in childhood and adolescence. Am. J. Clin. Nutr. 2002, 76, 653-658. [CrossRef] [PubMed]

33. Center for Disease Control and Prevention (CDC). Defining Children's Obesity—BMI for Children and Teens. 2018. Available online: https: / / www.cdc.gov / obesity/childhood/defining.html (accessed on 22 July 2021). 